\title{
THE IMPORTANCE OF SOIL FACTORS FOR CROPS IN AGRICULTURE
}

\author{
SayimbetovAlisher \\ Doctor of Philosophy (PhD) in Agricultural Sciences, Docent of the Department Farming, Selection \\ and Seed Breeding of Agricultural Crops, Karakalpakstan Institute of Agriculture and \\ Agrotechnology, Nukus, Karakalpakstan, Uzbekistan
}

Article DOI: https://doi.org/10.36713/epra9126

DOI No: 10.36713/epra9126

This article presents the high yields of crops due to the improvement of the factors and propertiesof soil that are necessary for plants. This is due to the fact that the application of organic fertilizers, ie composts, at 20 t/ha, the agrophysical and agrochemical properties of the soil are optimal, water, air, heat and nutrient regimesof the soil are improved at the level of plant demand. In this process, the growth, development and high yields of crops are ensured.

KEYWORDS: Agriculture, soil productivity, agrophysical properties, agrochemical properties, fertilizers, nutrients, moisture, soil fertility.

\section{INTRODUCTION}

Like any living thing, a plant needs certain conditions to grow, develop, andgive products. When these conditions are created, all the physiological, chemical, biochemical, and other processes that take place in the plant will be normal and will produce the expected yield.

The second basis of scientific farming is soil productivity. Although soil productivity is a natural property, it depends on the nutrients accumulated during soil formation, the physical properties of the soil, and the climatic conditions.

One of the factors determining soil fertility is organic matter. Organic matter is an important component of soil. Some of these substances are not replenished, while others are altered by decay, turning into a dark and complex organic humus, which is absorbed into the soil mineral.

Today, various fertilizers are widely used in the world to grow ecologically free products, increase soil productivity, improve its water-physical and agrochemical properties, and optimize the nutritional regime of agricultural crops. Countries around the world, such as the United States, China, Japan, India and Australia, are achieving high results in the effective use of multi-component fertilizers in agriculture. Organic fertilizers enrich the soil with humus and other nutrients and improve its agro- physical, water-physical properties, reduce environmental damage, as well as ensure high and quality yields from crops.

According to K. Mirzazhanov, Sh. Nurmatov [2], soil productivity depends onits physical, agrochemical, hydrothermal, reclamation, agro-technical and other features. The high content of humus in the soil depends on its productivity, as it contains nitrogen, phosphorus, potassium, carbon dioxide, and macro and micro elements necessary for the plant as a whole. Humus determines the macro and microstructural structure of the soilsteadiness to water, their amount (structure) in humus-rich soils increases, the growth of the structure optimizes the volume of the soil, improves water, air and microbiological conditions, and it brings into development of nutrition regime of crops. Organic fertilizers increase the amount of humus in the soil when applied in combination with mineral fertilizers.

Organic fertilizers are important in increasing the yield of crops. According to academic D.N.Pryanishnikov [3], the application of organic fertilizers to the soil improves the physical properties of the soil, the absorption propertiesand the buffering properties of the soilimprove. Organic fertilizers improve the life of microorganisms in the soil, that is, they increase the content of carbonates and other organic acids in the soil. Organic fertilizers in the soil 
changes the process of air exchange in the soil and normalizes the process of photosynthesis in plants. In addition, organic fertilizers improve the soil structure and facilitate the absorption of mineral fertilizers by plants.

Two Italian farms have been producing high-quality compost for 5 years in production research. For comparison, manure and mineral fertilizers were used.As a result of using composts NPK formsand organic matter content in soils were improved. In thevariants when organic fertilizerswere used instead of mineral fertilizers, air regime of the soil and the amount of nitrogenwere high and yield was increased.Taking potassium was high when manure was used. Organic fertilizers, especially compost, increase soil fertility. G. Gianfranco, M. Piero, A. Luigi, G. Carmen emphasize that when wastewas completely recycled, created high quality compostsand used correctly - it can give good results [4].

In the experiments of S. Boltaev [1], using mixed composts of different amount in soil increased the number of active elements in the soil, the movement of nitrogen in the soil layer 0-30 cmchanged from $7.50 \mathrm{mg} / \mathrm{kg}$ to $8.84 \mathrm{mg} / \mathrm{kg}$, phosphorus from $39 \mathrm{mg} / \mathrm{kg}$ to $44.8 \mathrm{mg} / \mathrm{kg}$, potassiumfrom $220 \mathrm{mg} / \mathrm{kg}$ to $300 \mathrm{mg} / \mathrm{kg}$. As a result of reducing the amount of mineral fertilizers (N-150, $\mathrm{P}-100$ and $\mathrm{K}-75 \mathrm{~kg} / \mathrm{ha}$ ) and adding an additional 21 24 tons of compost, economized $30-40 \mathrm{~kg} / \mathrm{ha}$ ofmineral fertilizers and compost, which was made by adding bentonite absorb water and elements dissolved in the water, and as a result of its distribution properties $800 \mathrm{~m}^{3}$ / ha water was economized.

Using composts of various wastes at a rate of 20 tons per hectare resulted in a decrease in soil capacity mass and an increase in porosity. Moreover, an increase in the amount of humus, total nitrogen and phosphorus in the soil was also achieved. In general, compost has proven to be one of the main sources as an organic fertilizer in increasing and maintaining soil fertility [5].

\section{METHODS OF CONDUCTING THE EXPERIMENT}

The experiments were carried out under typical soil conditions, using N-200 + P-140 + K-100 $\mathrm{kg} / \mathrm{ha}, 10$ and $20 \mathrm{t} / \mathrm{ha}$ of manure and 10 and $20 \mathrm{t} / \mathrm{ha}$ of compost.

Carrying out the experiments, phenological observations, taking samples of soil and plants and analyzing were studied on the basis of the following manuals: "Methods of agrochemical, agrophysical and microbiological experiments in field cotton regions", "Methodology of field vegetational experiences with cotton in the irrigational conditions", "Methods of agrochemical analysis of soil and plants of Central Asia", "Methods of carrying out field experiments", "Mehtodology of field experiments" of B.A.Dospexov.

\section{RESULTS OF THE RESEARCH}

One of the main indicators of soil productivity is its agrophysical properties. Basically, the mechanical composition, granularity, bulk density, porosity, water permeability, etc. of the soil. The physical properties of the soil and the physical processes that take place in it affect the appearance of the soil, its productivity, and the growth and development of plants.

Some scientists proved that while the soil is well supplied with nutrients, air and moisture, microbiological processes have also been shown to be active.

At the same time, due to various influences, the volume of the soil changes depending on the mass.

It is known from the literature that if the amount of fertilizer applied to the soil is increased, the volume of the soil isdecreased. It was determined that in variants $2-3$, when 10 and 20 t/ha of manure was used in addition to mineral fertilizers, the volume of soil in $0-30$ and $30-50 \mathrm{~cm}$ layers was found to be $0.04-0.06$ and $0.02-0.04 \mathrm{~g} / \mathrm{cm}^{3}$ less than in variant 1 , respectively. In the variants when 10 and $20 \mathrm{t} /$ ha of compost -2 applied per hectare, the volume of the above-mentioned soil layers in the ratio of 1,33-1,31 and 1,41-1,39 $\mathrm{g} / \mathrm{cm}^{3}$ was formed, and less than the first variant by 0,05-0,07 and 0,03$0,05 \mathrm{~g} / \mathrm{cm}^{3}$, respectively. Compared to composting standards, it was found to be less than 0.01-0.01 and $0.01-0.01 \mathrm{~g} / \mathrm{cm}^{3}$.

The porosity of the soil varies depending on its mass. The increase of soil porosity leads to the adaptation of the weather regime, which allows the roots of plants to grow better. In the $7^{\text {th }}$ variant with 20 tons of compost- 2 per hectare, the porosity in the $0-30$ and $30-50 \mathrm{~cm}$ layers of the soil is $53.3 \%$ and $50.7 \%$, respectively, these indicators are higher by 2.2 and $2.2 \%$ of the control (1) variant, were $0.4 \%$ and $0.3 \%$ higher from the variant (3) when 20 t/ha of manure was used. This is due to the fact that the water-physical condition of the soil can be improved if composts are used instead of only manure.

Factors involved in the formation of plant organs and influencing their growth, development, productivity, and product quality are called the life factors of cultivated plants in agriculture.

Plants thrive only when the processes of soil water transfer and transpiration are alternated. Knowing these laws of plant life, proper management of soil water regime and moderation of their 
maintenance measures will allow to use water efficiently.

Air is as important to plant life as any other factor. This is because when plants absorb carbon dioxide, they breathe and absorb oxygen. The $\mathrm{CO}_{2}$ released by plant roots when they breathe increases the solubility of many minerals. This helps the plants to get nutrients better. However, too much carbon dioxide can squeeze out the oxygen in the soil air, making it harder for the roots to breathe and reducing yields.

Heat is also needed for normal seed growth and development, as well as for the synthesis of organic matter. Soil temperature control is an important measure in increasing soil productivity and growing crops.

Organic fertilizers play an important role in improving the soil nutrition and ensuring the growth and development of plants.

The highest indicators of the amount of nitrate nitrogen, mobile phosphorus and metabolites under the influence of applied composts were obtained when compost- 2 was used in the amount of $20 \mathrm{t} / \mathrm{ha}$, they were $24.5 ; 33.6$ and $295 \mathrm{mg} / \mathrm{kg}$ on $0-30$ $\mathrm{cm}$ layer of soil, respectively, and comparing to the control variant $3.3 ; 3.8$ and $30 \mathrm{mg} / \mathrm{kg}$.

The relatively high impact of various composts applied to the development of cotton was observed when compost- 2 was applied at a rate of 20 $\mathrm{t} / \mathrm{ha}$, the number of fruitful branches were 15.2 and the number of buds was 12.9. These values are higher by 3.7 and 3.5 compared to the control, and 0.8 and 0.4 , compared to the application of manure at $20 \mathrm{t} / \mathrm{ha}$. Data on the effects of composts in recent years have also been obtained from the above laws, and it has been found that their effects are high for up to 3 years.

As a result of the applied composts, the highest cotton yield was obtained at 20 tons of compost-2 was used per hectare, with an average cotton yield of $37.1 \mathrm{c} / \mathrm{ha}$ in three years and an additional $6.7 \mathrm{c} /$ ha of cotton yield was obtained.

\section{CONCLUSION}

In agriculture, soil factors play an important role in the growth, development and quality of crops. The effect of organic fertilizers on improving these factors is high, which increases crop yields. The use of composts, in particular, improves the agrophysical and agrochemical properties of the soil, allowing plants to grow.

\section{REFERENCES}

1. Boltaev S. Compost made from local fertilizers. // Journal of Uzbek Agriculture. T.: 2009. №3. p. 24.
2. Mirzajanov $Q$., Nurmatov Sh. Improving soil fertility. // Agroilmjurnali. T.: 2008. №4 (8). p. 12.

3. Pryanishnikov D.N. Poems. // II. Frequency. M.: 1963. p. 712.

4. Gianfranco G., Piero M., Luigi A., Carmen G. Integrated waste management in a zone of northern Italy: compost production and use, and analytical control of compost soil, and crop. B 2006.41, №7b. P. 1203-1219.

5. Sayimbetov A., Elemesova N., Abdimuhammedalieva I.J. Increasing soil fertility. EPRA International Journal of Research \& Devolopment (IJRD). Volume: 5, Issue:9, India. April, 2020. p. 486-488. 